\title{
Control of protein structure and function through surface recognition by tailored nanoparticle scaffolds
}

\author{
Rui Hong ${ }^{\dagger}$, Nicholas O. Fischer ${ }^{\dagger}$, Ayush Verma ${ }^{\dagger}$, Catherine M. Goodman ${ }^{\dagger}$, \\ Todd S. Emrick ${ }^{\ddagger, *}$, Vincent M. Rotello ${ }^{\dagger,}$ \\ ${ }^{\dagger}$ Department of Chemistry, ${ }^{\ddagger}$ Department of Polymer Science and Engineering, \\ University of Massachusetts Amherst, Amherst, MA 01003

\section{Supporting Information}

\section{Synthesis of ligands}

Ligand 1 was prepared using a literature procedure, ${ }^{1}$ and ligand $\mathbf{2}$ was prepared as follows:

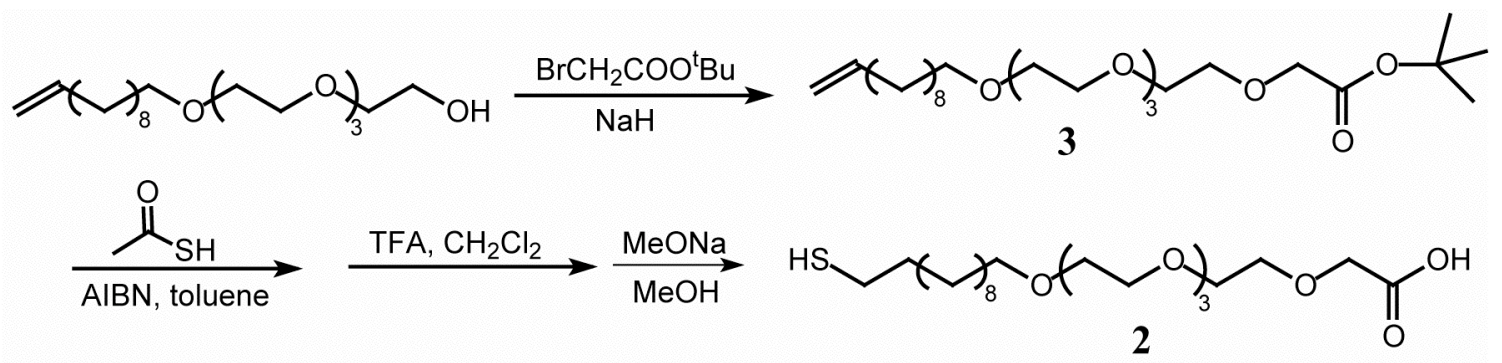

$\mathrm{NaH}$ (57-63\% oil dispersion, $0.48 \mathrm{~g}, 12 \mathrm{mmol}$ ) was added to a $20 \mathrm{ml} \mathrm{DMF}$ solution of undec-1-en-11-yltetra(ethylene glycol $)^{1}(2.07 \mathrm{~g}, 6 \mathrm{mmol})$ at $0{ }^{\circ} \mathrm{C}$. The mixture was stirred for about 10 minutes and tert-butyl bromoacetate $(1.17 \mathrm{~g}, 9 \mathrm{mmol})$ was added dropwise. The mixture was stirred at RT overnight. The mixture was added $20 \mathrm{ml}$ of water and was extracted with ethyl acetate $\left(40 \mathrm{ml} \_3\right)$. Combined organic was washed with water and brine, and dried over $\mathrm{MgSO}_{4}$. Evaporation of the solvent afforded ester 3 as a clear oil. It was purified by flash column chromatography to give $1.66 \mathrm{~g}$ product ( $60 \%$ yield).

${ }^{1}$ H NMR $\left(300 \mathrm{MHz}, \mathrm{CDCl}_{3}\right)$ : _ (ppm) $5.8(\mathrm{~m}, 1 \mathrm{H}), 4.90-5.02(\mathrm{~m}, 2 \mathrm{H}), 4.02(\mathrm{~s}, 2 \mathrm{H}), 3.58-$ $3.70(\mathrm{~m}, 16 \mathrm{H}), 3.44(\mathrm{t}, 2 \mathrm{H}, \mathrm{J}=6.9 \mathrm{~Hz}), 2.03(\mathrm{~m} 2 \mathrm{H}), 1.47(\mathrm{~s}, 9 \mathrm{H}), 1.59-1.23(\mathrm{~m}, 14 \mathrm{H})$.

${ }^{13}$ C NMR (75 MHz, $\mathrm{CDCl}_{3}$ ): _ (ppm) 26.29, 28.32, 29.14, 29.33, 29.64, 29.68, 29.75, $29.85,34.02,69.26,70.27,70.79,70.82,70.94,71.76,81.72,114.31,139.45,169.89$.

To a solution of $3(1.6 \mathrm{~g}, 3.4 \mathrm{mmol})$ in $10 \mathrm{ml}$ toluene was added $0.16 \mathrm{~g}(1 \mathrm{mmol})$ of AIBN. The mixture was purged with Ar for 10 minutes, then $1.3 \mathrm{ml}$ of thioacetic acid $(1.37 \mathrm{~g}, 18 \mathrm{mmol})$ was added. The solution was heated at $100-110^{\circ} \mathrm{C}$ for 8 hours under $\mathrm{N}_{2}$ and then concentrated in vacuum. The residue from the above reaction was added into $15 \mathrm{ml}$ of 1:1 TFA: $\mathrm{CH}_{2} \mathrm{Cl}_{2}$ mixture and stirred at room temperature overnight. The mixture was coevaporated with toluene twice, diluted with $\mathrm{CH}_{2} \mathrm{Cl}_{2}$ and washed with water until the aqueous was neutral. Solvent was removed by rotary evaporation and the residue was then dissolved in $60 \mathrm{ml}$ of methanol and purged with Ar for at least 10 minutes. $\mathrm{MeONa}$ ( $3 \mathrm{ml}$ of $25 \mathrm{wt} \% \mathrm{MeONa}$ in $\mathrm{MeOH}, 13 \mathrm{mmol}$ ) was purged with $\mathrm{Ar}$ and added into the thioester solution. The mixture was stirred under Ar overnight and quenched with acetic acid. The product was extracted with chloroform and washed with brine. Evaporation of the solvent afforded a pale yellow oil which was purified by flash column chromatography to give $2(0.62 \mathrm{~g}, 40 \%$ yield $)$.

\footnotetext{
${ }^{1}$ Pale-Grosdemange, C.; Simon, E. S.; Prime, K. L.; Whitesides, G. M. J. Am. Chem. Soc. 1991, 113, 12-20
} 
${ }^{1}$ H NMR (300 MHz, CDCl $)$ : _ (ppm) 4.14 (s, 2H), 3.73-3.58 (m, 16H), 3.44 (t, 2H, $\mathrm{J}=6.8 \mathrm{~Hz}), 2.50(\mathrm{~m}, 2 \mathrm{H}), 1.58-1.23(\mathrm{~m}, 18 \mathrm{H}), 1.29(\mathrm{t}, 1 \mathrm{H}, \mathrm{J}=7.8 \mathrm{~Hz})$.

${ }^{13}$ C NMR (75 MHz, $\left.\mathrm{CDCl}_{3}\right)$ : _ $_{-}$(ppm) 24.85, 26.23, 28.57, 29.25, 29.65-29.75, 34.24, $65.46,70.04,70.42,70.51,70.56,70.72,70.77,71.27,71.76,172.30$.

IR $\left(\mathrm{CHCl}_{3}\right.$ film, $\left.\mathrm{cm}^{-1}\right): 3012,2929,2856,1738$.

HRMS (FAB, M+1): calculated: 439.2730, found: 439.2762 .

\section{General procedure for ligand exchange:}

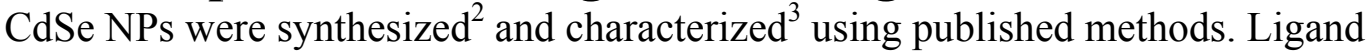
exchange was performed to replace trioctyl phosphine oxide (TOPO) on the nanoparticle surface with ligand $\mathbf{1}$ and $\mathbf{2}$. About $20 \mathrm{mg}$ of TOPO covered CdSe nanoparticles were added to a solution of $\sim 40 \mathrm{mg}$ thiol-OEG ligand in methanol. The mixture was adjusted to $\mathrm{pH}=9-10$ by the addition of tetramethylammonium hydroxide. An optically clear orange/red solution formed immediately upon adding TOPO covered nanoparticles into the ligand solution, indicating a quick and effective replacement of hydrophobic TOPO by hydrophilic OEG. The mixture was heated at $70{ }^{\circ} \mathrm{C}$ overnight, and the nanoparticles were precipitated in diethyl ether. Excess ligands were removed by repeated dissolution in methanol and precipitation in ether. MUA covered NPs were prepared by the same method to give MUA-NP.

The resulting 1-NP and 2-NP are highly soluble in $\mathrm{MeOH}$, partially soluble in chloroform or tetrahydrofuran, and insoluble in ether or hexanes. The precipitated nanoparticles were dried swiftly under a flow of $\mathrm{N}_{2}$, then dissolved in $\mathrm{D}_{2} \mathrm{O}$ for NMR analysis. ${ }^{1} \mathrm{H}$ NMR showed broadening of the corresponding peaks of the thioalkylated OEG ligands after exchange and no evidence of TOPO, as the methyl resonance of the initial TOPO molecules $(\sim 0.9 \mathrm{ppm})$ was not seen in the spectrum of the OEG covered nanoparticle in $\mathrm{D}_{2} \mathrm{O}$. Figure $\mathrm{S} 1$ and $\mathrm{S} 2$ shows representative ${ }^{1} \mathrm{H}$ NMR spectrum of 1-NP and 2-NP. NP stock solutions were made in $5 \mathrm{mM}$ sodium phosphate buffer $(\mathrm{pH}=7.4)$ and the concentrations were determined by using the reported extinction coefficient. ${ }^{4}$

The synthesis of the mixed monolayer covered CdSe was similar to the above ligand exchange method. The percentage of 2 was estimated by the integration of the $-\mathrm{CH}_{2}$ group $\square$ to the $\mathrm{COOH}$ over the protons of the EG4. Figure S3-S5 shows representative spectrum of mixed monolayer covered NPs. The calculation of ligand $\mathbf{2}$ percentage based on the ${ }^{1} \mathrm{H}$ NMR integration is as follow:

$$
\text { COOH } \%=\text { EG4Integraton } \square 20 / \text { EG4Integration }
$$

\footnotetext{
${ }^{2}$ Peng, Z.A.; Peng, X.G. J. Am. Chem. Soc. 2001, 123, 183-184

${ }^{3}$ Peng, X. G.; Wickham, J.; Alivisatos, A. P. J Am Chem Soc 1998, 120, 5343-5344

${ }^{4}$ Leatherdale, C. A.; Woo, W. K.; Mikulec, F. V.; Bawendi, M. G. J. Phys. Chem. B 2002, 106, 7619-7622.
} 
Figure S1: 1-NP

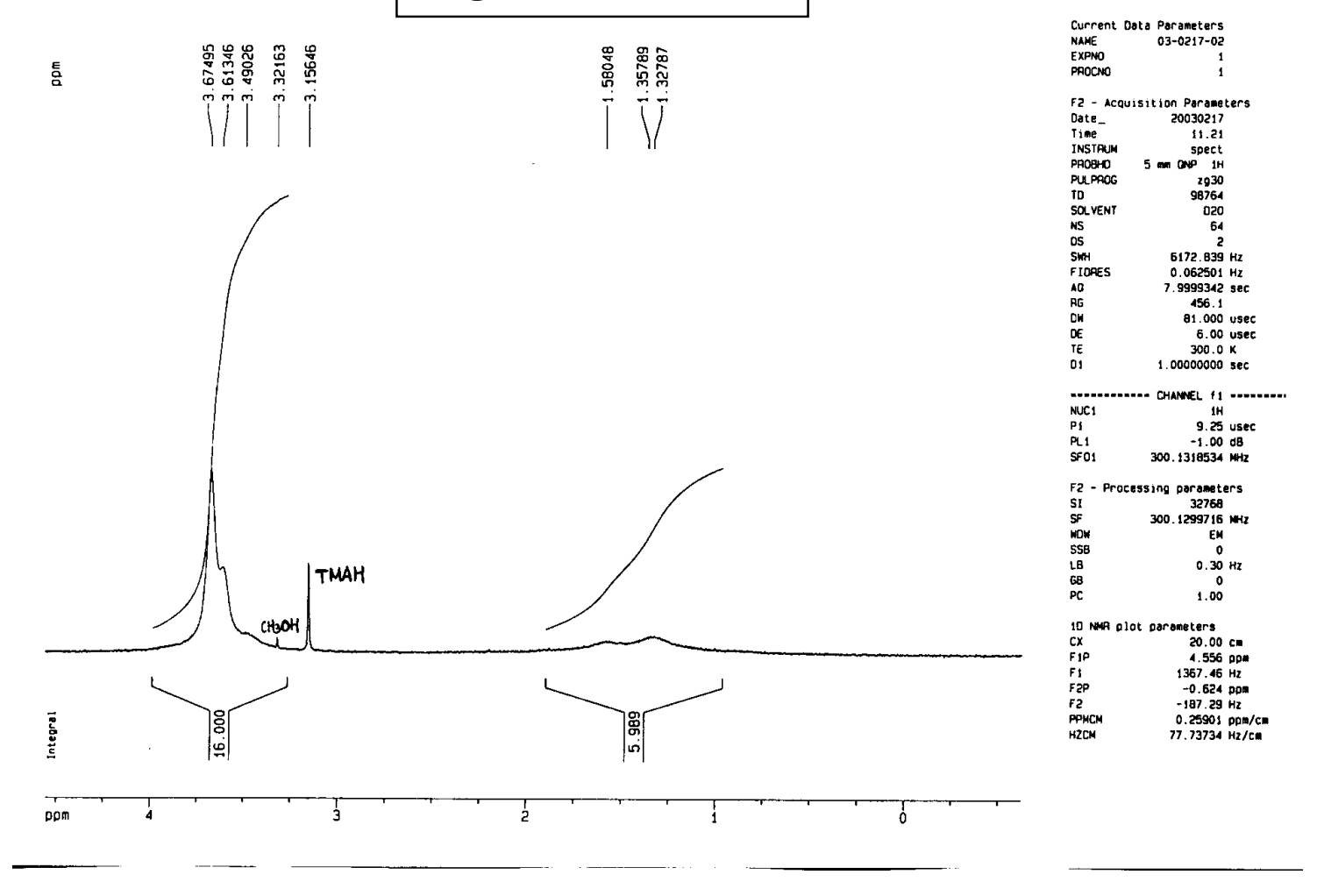

\section{Figure S2: 2-NP}
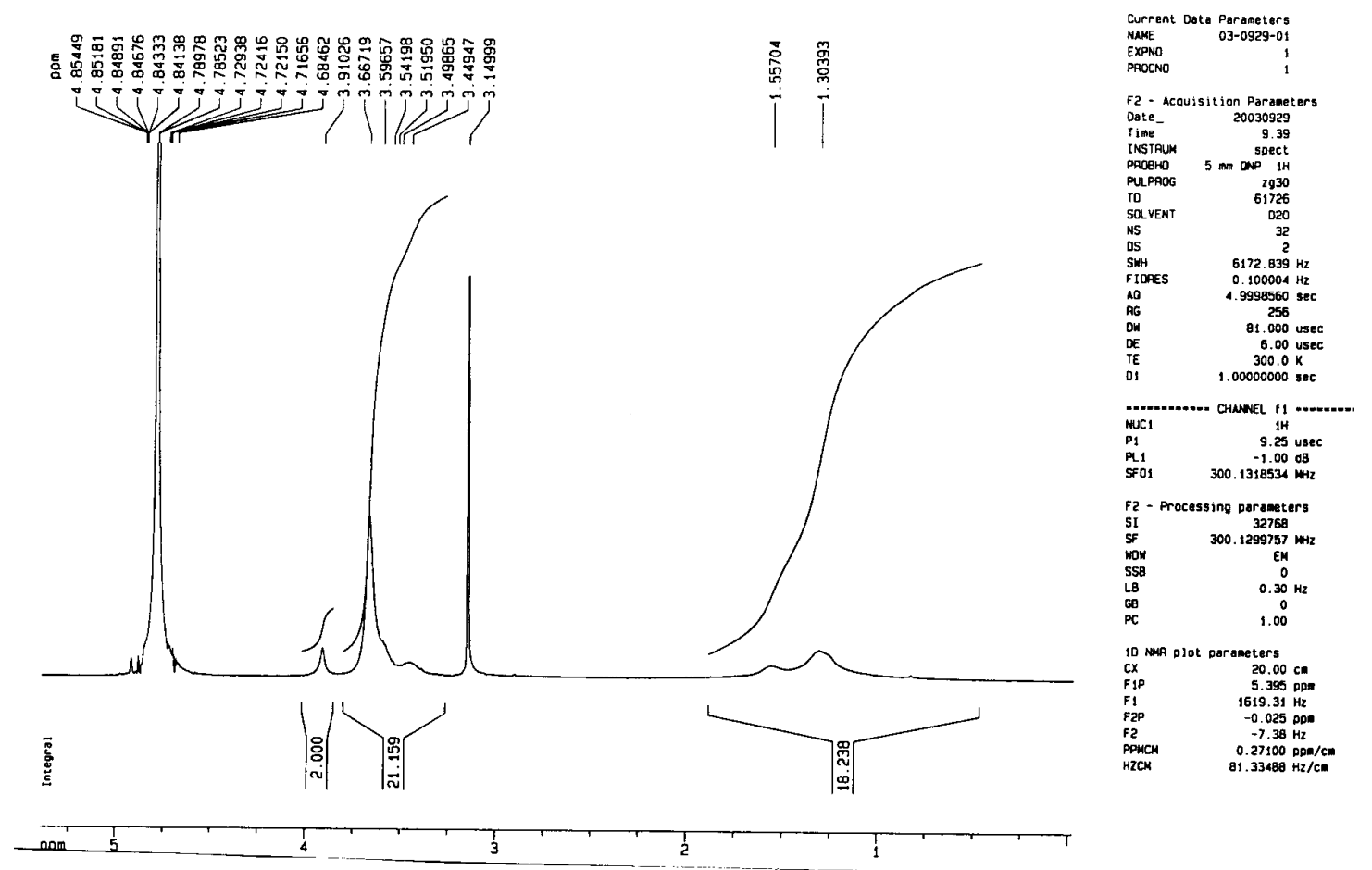
Figure S3: TTMM1 NP

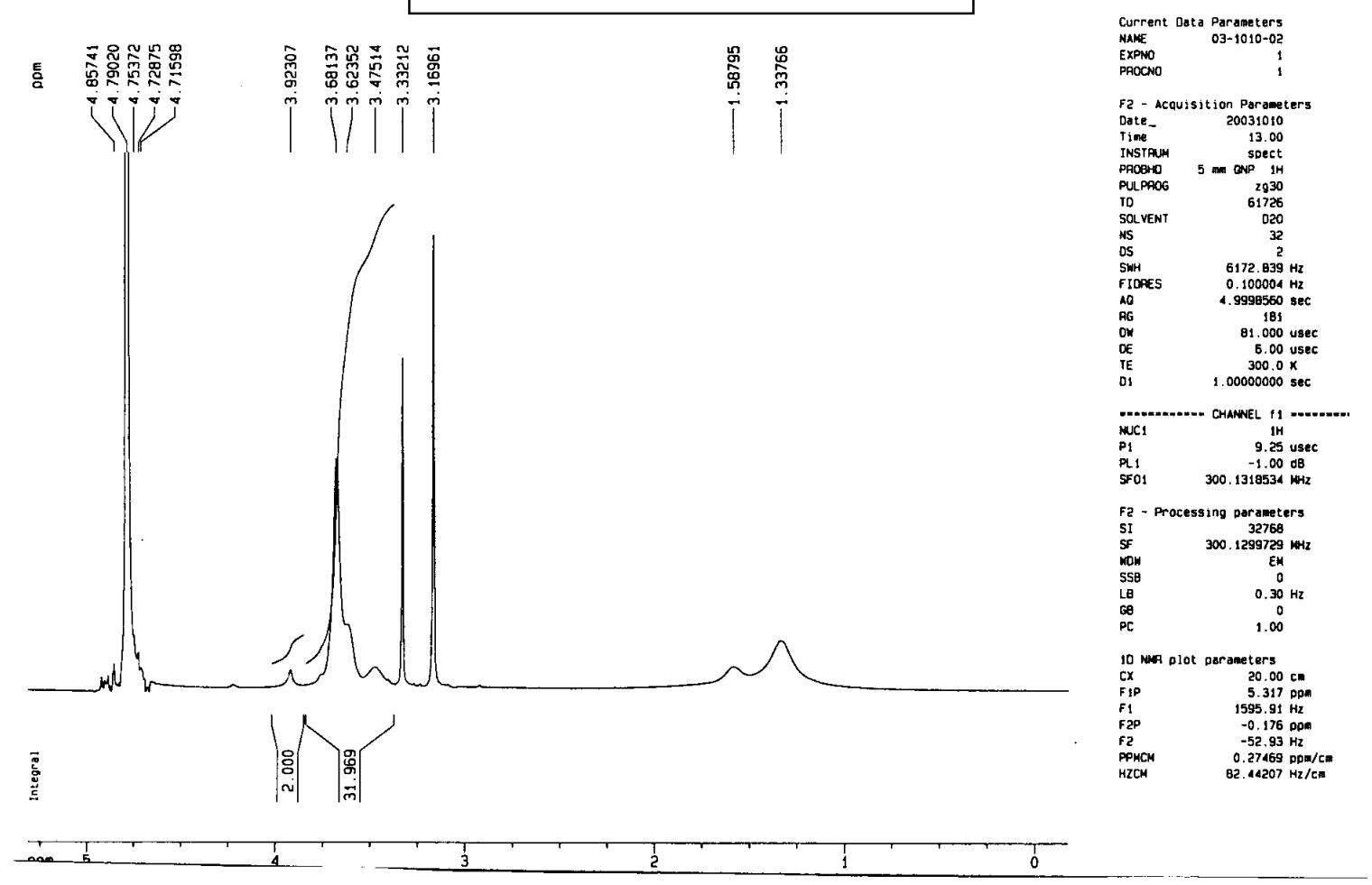

Figure S4: TTMM2 NP

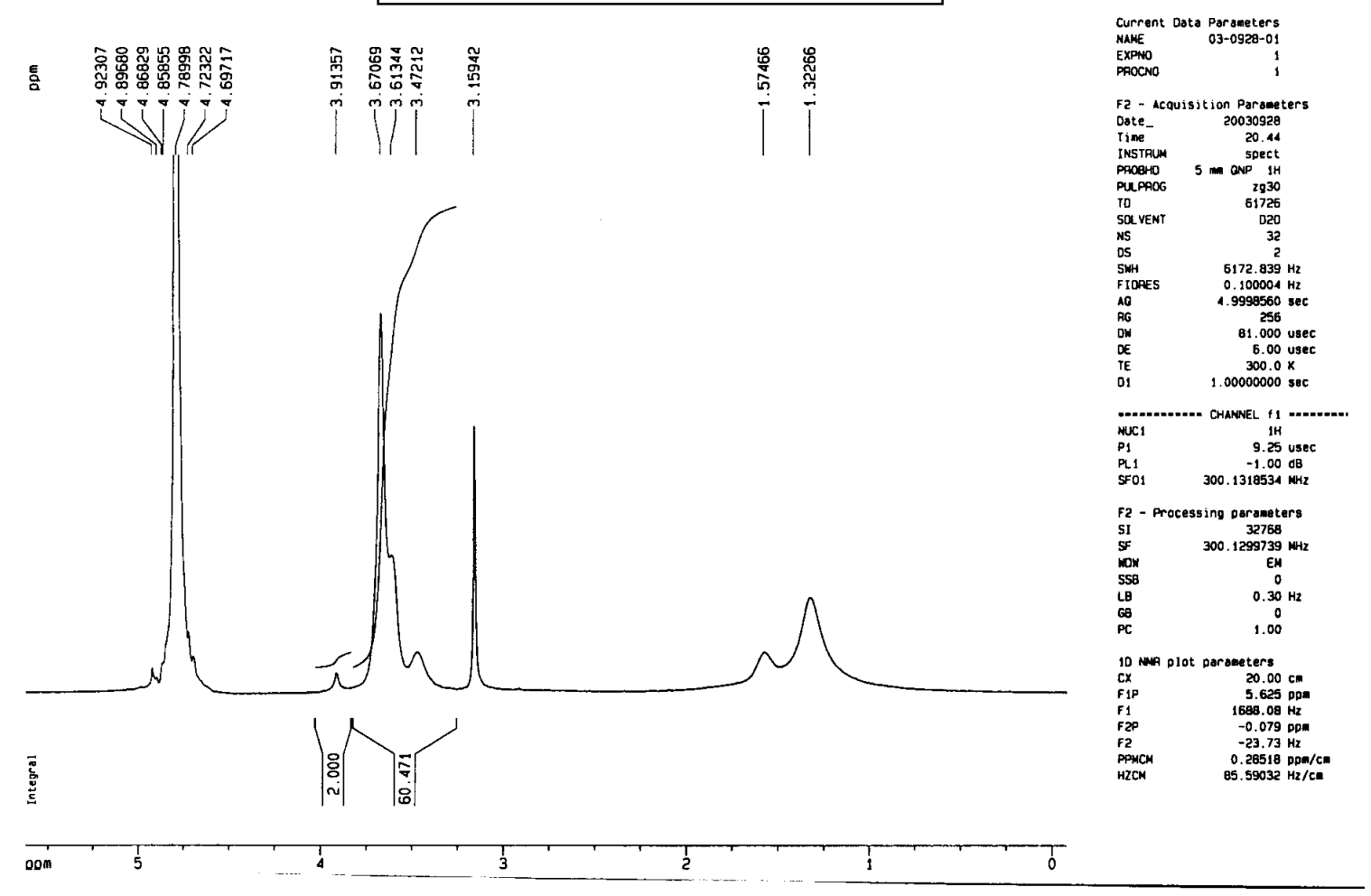




\section{Figure S5: TTMM3 NP}

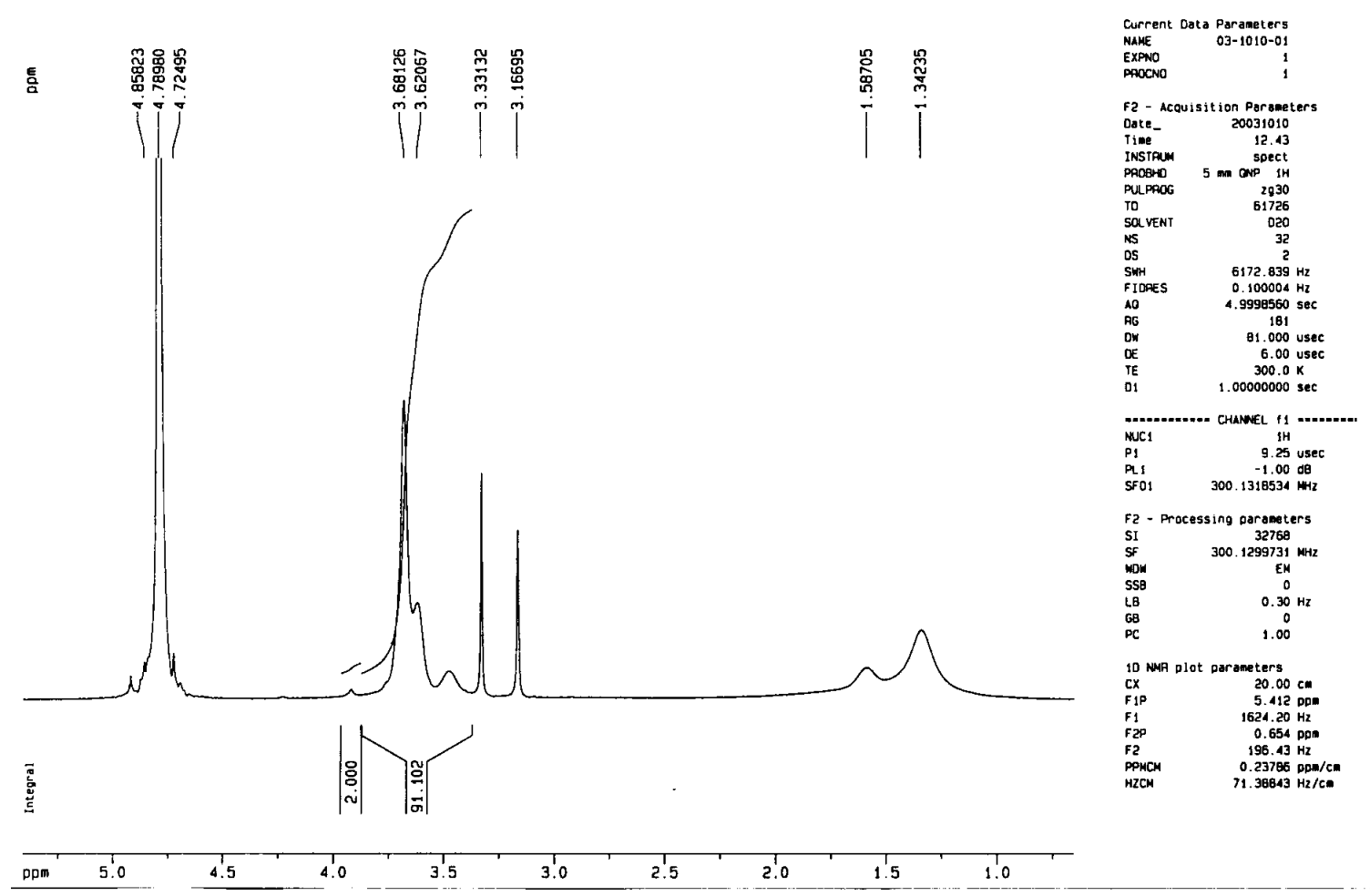

The sharp peak at $3.3 \mathrm{ppm}$ is due to the residue $\mathrm{MeOH}$.

The sharp peak at $3.16 \mathrm{ppm}$ is due to tetramethylammonium salt, which was added in the ligand exchange reaction. 
Figure S6: Determination of binding stoichiometry

See text for details.

2-NP:ChT ratio

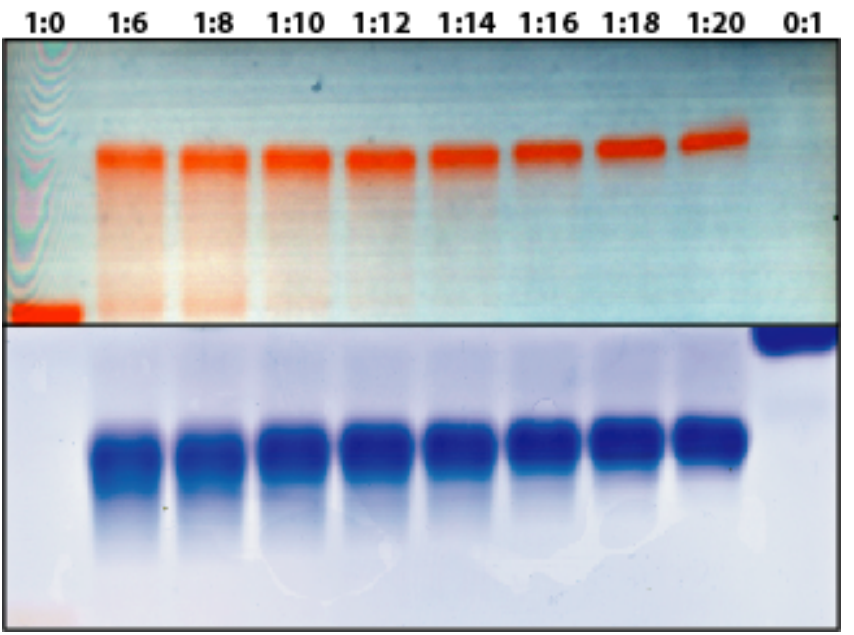

MUA:ChT ratio

$\begin{array}{llllllllll}1: 0 & 1: 0.5 & 1: 1 & 1: 2 & 1: 4 & 1: 6 & 1: 8 & 1: 10 & 1: 12 & 0: 1\end{array}$

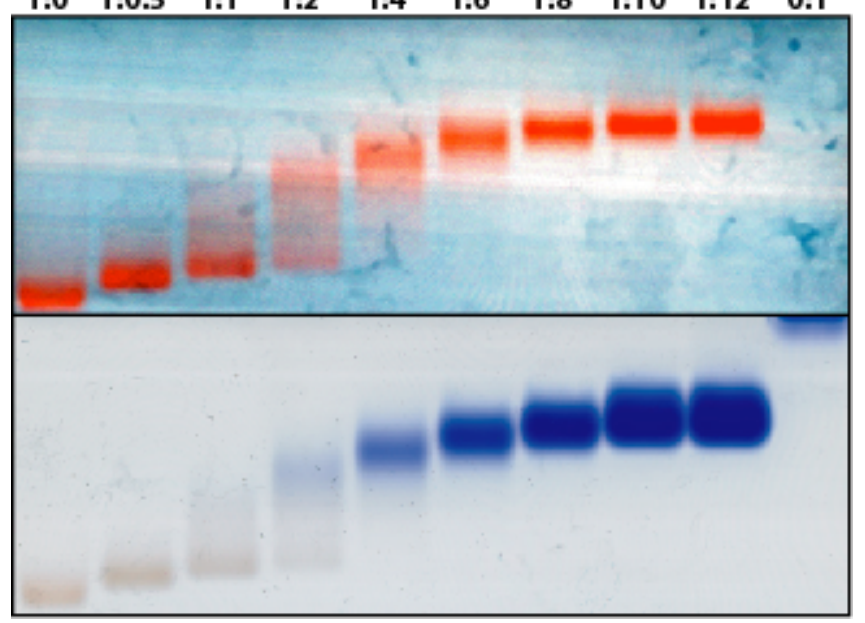

